\title{
Research on the Measurement and Driving Factors of Manufacturing Export Embodied Carbon between China and the Countries along "the Belt and Road"
}

\author{
Yan Li, Kaiyue Lin, Qingbo Huang* \\ School of Shipping Economics and Management, Dalian Maritime University, China
}

Received: 13 February 2020

Accepted: 31 May 2020

\begin{abstract}
With the expansion of China's manufacturing export trade to the countries along "the Belt and Road", the energy consumption and carbon emissions of China's manufacturing process from production to export caused by these countries will also increase. This paper adopts the MRIO model to calculate the export embodied carbon emissions of China's manufacturing export trade from 2000 to 2015, and further adopts the LMDI method to study the driving factors of export embodied carbon emissions of China's manufacturing export trade from three aspects: scale effects, structural effects and technical effects. The results indicate an increasing trend of the export embodied carbon emissions from 2000 to 2015. Scale effect has a pulling effect on the export embodied carbon emissions, while structural and technical effects have a restraining effect mostly on manufacturing. Therefore, in order to facilitate the entire process in the manufacturing chain of China's manufacturing industry, which includes the acquisition of raw materials, manufacturing, and transportation, and to achieve green development, it is necessary for China to optimize the manufacturing export structure and reduce the carbon emissions intensity to reduce the embodied carbon emissions of manufacturing industries to the countries along "the Belt and Road".
\end{abstract}

Keywords: LMDI method, embodied carbon, MRIO model

\section{Introduction}

In 2017, the total import and export volume between China and countries along "the Belt and Road" reached $\$ 1,440.32$ billion, a year-on-year increase of $13.4 \%$, and a 5.9 percentage point higher than the overall

*e-mail: huangqingbo@dlmu.edu.cn growth rate of China's foreign trade, accounting for $36.2 \%$ of China's total trade volume. From the above, China's exports to "the Belt and Road" countries was $\$ 774.26$ billion, a year-on-year increase of $8.5 \%$ and accounting for $34.1 \%$ of China's total exports [1]. From the perspective of trade structure, in 2017, China's exports to "the Belt and Road" countries mainly focused on mechanical and electrical products, including electrical machinery, electrical equipment and boiler 
machinery, accounting for $23.2 \%$ and $15 \%$ of China's exports to "the Belt and Road" countries respectively. The export growth of electrical machinery and electrical equipment increased by $15.8 \%$ compared with 2016. It can be seen that China's exports to "the Belt and Road" countries mainly focus on manufacturing industry, which is often one of the main industries consuming energy. Therefore, as the scale of China's manufacturing export to the countries along "the Belt and Road" continues to expand, the energy consumption and carbon emissions of China's manufacturing industry will also continue to increase. Under such circumstances, how much carbon emissions are involved in the production and export of China's manufacturing industry caused by consumption in countries along "the Belt and Road"? How do the carbon emissions involved in these manufacturing export trade processes change and what are the drivers to their changes? The solution of the above problems will enable China to achieve green manufacturing production and green development in the process of trade with countries along "the Belt and Road".

\section{Literature Review}

Under the background and trend of economic globalization and international trade, scholars gradually find that the change of consumption demand of a product consuming country will lead to the change of energy consumption and carbon emissions of the product producing country. Although the carbon emissions of consumer countries themselves are small, the associated energy consumption and carbon emissions caused by their trade may be large [2-4]. Since then, the issue of carbon emissions embodied in trade has attracted wide attention from scholars. According to the UNFCCC, embodied carbon is defined as "the $\mathrm{CO}_{2}$ emitted during the process from the acquisition of raw materials, manufacturing, processing, and transportation to becoming a product purchased by consumers" [5]. Measured from the perspective of embodied carbon, the carbon dioxide content directly and indirectly emitted by products in the whole production chain can be included. The export embodied carbon refers to the carbon directly and indirectly emitted in the whole production chain of producing countries in order to produce exported products. With the manufacturing export trade between China and countries along "the Belt and Road" intensifies, China's export embodied carbon to countries along "the Belt and Road" will consequently increase. Exploring the driving factors of the carbon change embodied in export will help China's manufacturing industry reduce the carbon emissions directly and indirectly produced in the manufacturing process caused by the consumption of countries along "the Belt and Road" under the existing trade scale of exports to countries along "the Belt and Road".
From the current research, domestic and foreign scholars mainly use the input-output method to calculate the carbon embodied in trade. The input-output method is divided into single-region input-output method (SRIO) and multi-region input-output method (MRIO). The SRIO model is a method of studying the embodied carbon emissions associated with final consumption in a country or region using a country's or region's inputoutput table. Ma and Chen (2010) used the singleregion input-output model to estimate China's embodied carbon emissions from 2000 to 2009, and analyzed the reasons for the increasing net embodied carbon emissions difference [6]. The SRIO model cannot reflect the trade links and industrial links between countries (regions) and departments, making the measurement results deviate greatly. With the in-depth research on the carbon emissions embodied in regional trade, the limitations of the SRIO model have become apparent, and the use of MRIO model, which can reflect the relationship between regions, has gradually increased [7]. Yan, Zhao and Wang (2013) established a multiregion input-output model to measure the embodied carbon in China's foreign trade and compared their production and consumption emissions responsibilities. They found that China's import and export trade embodied a large amount of $\mathrm{CO}_{2}$ emissions, and China was a typical net exporter of embodied carbon, with the embodied carbon in export far exceeding the embodied carbon in import [8]. Pang, Shi, Xie and Gao (2015) constructed a global multi-regional input-output table, and calculated that in 2004 and 2007, China's carbon emissions based on the production side were more than $15 \%$ higher than that of the consumer side, and China was a net exporter of embodied carbon, among which the top three industries with the highest embodied carbon exports were equipment manufacturing, textile and garment industry [9].

As for the research on the influencing factors of trade embodied carbon emissions, the LMDI method is mostly used. Li, Cong, and Shao (2018) used the LMDI method to decompose the effects, and studied the driving effects of aquatic product trade development on the embodied carbon emissions from three aspects: scale effect, structural effect and intensity effect [10]. In the decomposition of influencing factors, different scholars have different decomposition of influencing factors based on the content of their research. Yan, Zhao and Wang (2012), Pan and Wei (2016) decomposed factors into scale effect, structural effect and technical effect [11, 12]; Deng and Chen (2014), Li and Chen (2010) believed that the direct carbon emissions coefficient, intermediate production technology, trade structure and total trade volume caused changes in trade embodied carbon emissions [13, 14]; Zhang (2017) decomposed the influencing factors into technological change, industrial association change and trade volume change [15]; Wang (2017) decomposed factors into carbon emissions intensity effect, technical effects, population size effect, consumption structural effect 
and consumption scale effect, etc. [16]. The effect of these factors on the embodied carbon varies from one scholar to another. Zhao and Wang (2014) conducted factor decomposition and found that during 1995-2009, for the change of embodied carbon in China's export to Japan, scale effect promoted the growth of embodied carbon, technical effect promoted the reduction of embodied carbon, and structural effect had relatively small influence [17]. Qian and Yang (2016) conducted an inter-temporal comparison of China's export embodied carbon to East Asia in 1997-2002, 2002-2007 and 2007-2012. The results showed that the vertical division of labor in East Asia led to the growth of China's embodied carbon emissions, and although the increase in China's energy efficiency had a decreasing effect on the increase in embodied carbon emissions, the reduction was significantly narrowed. The deterioration of trade structure and expansion of trade scale were important factors for the embodied carbon growth of China's exports to East Asia [18].

Most scholars calculate the trade embodied carbon of China based on different input-output methods, among which the MRIO model is most preferred by scholars because it can explore the trade embodied carbon relationship between multiple countries or regions. On this basis, due to the reasons of simple operation, low data requirements, and effective elimination of residual and other impacts, most scholars use LMDI method to explore the influencing factors of trade embodied carbon, and these studies play an important role in this paper.

In summary, part of the current research focuses on the comparative analysis of the embodied carbon transfer in foreign trade between China and the developed regions, and uses this to explore the basis for sharing liability for emissions reduction between developing and developed countries. Some studies also focus on the calculation of embodied carbon emissions and its driving factors in China's foreign trade, so as to explore the environmental costs of "consumption abroad, borne at home"; while for the consumption by countries along "the Belt and Road", the research on environmental costs borne by China is relatively lacking. Under the trend of deepening manufacturing trade between China and countries along "the Belt and Road", how China can control embodied carbon emissions and realize green production and green development in the manufacturing industry remains a topic to be studied.

Compared with previous studies, this paper's main contributions are as follows: (1) This paper will study the countries along "the Belt and Road" as export objects of China's embodied carbon, and explore the carbon dioxide emissions and consumption from the countries along "the Belt and Road". The driving factors are conducive to the targeted recommendations on reducing China's export carbon emissions from the perspective of "the Belt and Road" initiative. (2) The research object of this paper is specific to manufacturing industry, which is not only the industry with the largest export scale to the countries along "the Belt and Road", but also the industry with the largest energy consumption. Focusing on manufacturing industry can provide ideas for promoting the development of manufacturing industry. Therefore, this paper adopts the method of MRIO-LMDI to explore the embodied carbon emissions of manufacturing exports of China to the countries along the "the Belt and Road" and its main driving factors from the perspective of total and sub-sectors, so as to provide the basis for China to reduce the embodied carbon emissions of manufacturing exports and realize "the Green Belt and Road".

\section{Methods and Data Sources}

\section{Methods}

\section{MRIO Model}

The input-output method is a basic method to evaluate the carbon embodied in trade, which can measure the direct and indirect carbon emissions in the process of product production. The multi-regional input-output model used by Yan and Zhao to study the carbon embodied in China's foreign trade and emissions liability can be used to describe the trade relationship between regions [8]. In the input-output analysis, the total output $\mathrm{x}$ can be expressed as:

$$
X=A x+y
$$

...where $\mathrm{A}$ is the direct consumption matrix and $\mathrm{y}$ is the final use column vector. If $\mathrm{y}^{\mathrm{d}}$ is the product column vector of domestic production and consumption, $\mathrm{y}^{\mathrm{ex}}$ is the export column vector and $\mathrm{M}$ is the import column vector, then:

$$
y=y^{d}+y^{e x}-M
$$

A country's import can be divided into two parts: intermediate product import and final consumption product import, namely:

So:

$$
\mathrm{M}=\mathrm{A}^{\mathrm{im}} \mathrm{x}+\mathrm{y}^{\mathrm{im}}
$$

$$
x=A^{d} x+A^{i m} x+y^{d}+y^{e x}+y^{i m}-M
$$

In this way, equation (3) can be expressed as:

$$
x=A^{d} x+y^{d}+y^{e x}
$$

According to the linear assumption of input-output analysis, the output of a country can be expressed as:

$$
x=\left(I-A^{d}\right)^{-1}\left(y^{d}+y^{e x}\right)
$$


Since $\mathrm{CO}_{2}$ emissions can cause global climate change, the environmental impacts of production and consumption need to be studied separately, which requires the establishment of multi-regional models to measure the carbon embodied in traded products. If there are $m$ countries or regions, according to the MRIO model, the output of each country can be expressed as:

$$
\left(\begin{array}{c}
x_{1} \\
x_{2} \\
x_{3} \\
\ldots \\
x_{m}
\end{array}\right)=\left(\begin{array}{ccccc}
A_{11} & A_{12} & A_{13} & \ldots & A_{1 m} \\
A_{21} & A_{22} & A_{23} & \ldots & A_{2 m} \\
A_{31} & A_{32} & A_{33} & \ldots & A_{3 m} \\
\ldots & \ldots & \ldots & \ldots & \ldots \\
A_{m 1} & A_{m 2} & A_{m 3} & \ldots & A_{m m}
\end{array}\right)\left(\begin{array}{c}
x_{1} \\
x_{2} \\
x_{3} \\
\ldots \\
x_{m}
\end{array}\right)+\left(\begin{array}{l}
\sum y_{1 j} \\
\sum y_{2 j} \\
\sum y_{3 j} \\
\ldots \\
\sum y_{m j}
\end{array}\right)
$$

...where, $x_{j}$ is the output of each department in country $\mathrm{j}$; $\mathrm{A}_{\mathrm{ij}}$ is the input matrix from country $\mathrm{i}$ to country $\mathrm{j}$; $\mathrm{Y}_{1 \mathrm{j}}$ represents the export of country 1 to country $j$; $Y_{i j}$ is the product produced by country $i$ and consumed by country j. Limited by the amount of data, equation (7) needs to be simplified on the premise of not causing a large error to the calculation results. This paper assumes that country 1 trades with all other countries, but there is no trade between other countries. In this way, equation (7) can be written as:

$$
\left(\begin{array}{c}
x_{1} \\
x_{2} \\
x_{3} \\
\ldots \\
x_{m}
\end{array}\right)=\left(\begin{array}{ccccc}
A_{11} & A_{12} & A_{13} & \ldots & A_{1 m} \\
A_{21} & A_{22} & 0 & \ldots & 0 \\
A_{31} & 0 & A_{33} & L & 0 \\
\ldots & \ldots & \ldots & \ldots & \ldots \\
A_{m 1} & 0 & 0 & \ldots & A_{m m}
\end{array}\right)\left(\begin{array}{c}
x_{1} \\
x_{2} \\
x_{3} \\
x_{m}
\end{array}\right)+\left(\begin{array}{c}
y_{11}+\sum_{j \neq 1} y_{1 j} \\
y_{21} \\
y_{31} \\
\ldots \\
y_{m 1}
\end{array}\right)
$$

Because:

$$
y_{1}^{e x}=\sum_{j \neq 1}\left(A_{1 j}^{i n} x_{j}+y_{1 j}\right)
$$

In this way, equation (8) can be simplified as:

$$
\left(\begin{array}{c}
x_{1} \\
x_{2} \\
x_{3} \\
\ldots \\
x_{m}
\end{array}\right)=\left(\begin{array}{ccccc}
A_{11} & 0 & 0 & \ldots & 0 \\
0 & A_{22} & 0 & \ldots & 0 \\
0 & 0 & A_{33} & \ldots & 0 \\
\ldots & \ldots & \ldots & \ldots & \ldots \\
0 & 0 & 0 & \ldots & A_{m m}
\end{array}\right)\left(\begin{array}{c}
x_{1} \\
x_{2} \\
x_{3}
\end{array}\right)+\left(\begin{array}{c}
y_{11}+y_{1}{ }^{e x} \\
M_{21} \\
M_{31} \\
\ldots \\
M_{m 1}
\end{array}\right)
$$

The aim of this paper is to study the embodied carbon in China's foreign trade. Therefore, it is assumed that China is country 1 , and only the final carbon emissions used in China are considered. When $i>1$, $\mathrm{y}_{\mathrm{i}}=0$. Thus, China's output can be expressed as:

$$
x_{1}=A_{11} x_{1}+y_{11}+y_{1}^{e x}=\left(I-A_{11}\right)^{-1}\left(y_{11}+y_{1}^{e x}\right)(\text { When } \mathrm{i}=1)
$$

Outputs of other countries are expressed as:

$$
x_{i}=A_{i i} x_{i}+M_{i 1}=\left(I-A_{i i}\right)^{-1} M_{i 1} \quad(\text { When } \mathrm{i} \neq 1)
$$

If China's direct emissions coefficient is $E_{1}$, then China's export embodied carbon emissions $\mathrm{f}_{1}^{\text {ex }}$ is:

$$
f_{1}^{e x}=E_{1}\left(I-A_{11}\right)^{-1} y_{1}^{e x}
$$

\section{LMDI Method}

In this paper, LMDI method is used to analyze the driving factors of China's manufacturing export embodied carbon emissions [19, 20]. It mainly draws on the model used by Copeland and Taylor to study environmental pollution and the carbon emission effect model used by Hou, Cai and Yang to study the relationship between embedded global value chain and China's trade implied carbon emissions [21, 22]. Based on the original model, this paper eliminated the factor of global value chain (GVC), so that the carbon emission effect model remained unchanged in the derivation process. The main reason is that GVC will indirectly influence the trade embodied carbon emissions through the trade scale, trade structure and technology level [23], and this paper studies the direct influencing factors of trade embodied carbon emissions, so the original model is simplified. From microeconimics' perspective, the general equilibrium model is used to derive and analyze the carbon emission supply and carbon emission demand, and obtain the general equilibrium solution of the carbon emission market. According to the model derivation results, the influencing factors of carbon emissions include technological level, economic structure, and economic scale. Specifically, the carbon emission effect can be decomposed into three effects. First, the technical effect, if the carbon emission intensity of the product is reduced, the carbon emission is reduced if other conditions remain unchanged. Second, the structural effect, changing the share of goods in the economy also changes carbon emissions. Third, the scale effect, the expansion of economic scale will increase carbon emissions if other conditions remain unchanged.

The LMDI method decomposes the energy variation into scale effect, structural effect and technical effect. Based on the characteristics of the LMDI method, it decomposes the export embodied carbon emissions of China's manufacturing, and calculates the contribution values and contribution rates of scale effect, structural effect and technical effect. The carbon emissions embodied in China's manufacturing export can be decomposed into: 


$$
C^{e x}{ }_{j}=\frac{C^{e x}{ }_{j}}{e_{j}} * \frac{e_{j}}{E} * E=T^{e x} * S^{e x} * M^{e x}
$$

In the formula, $\mathrm{C}^{\mathrm{ex}}{ }_{\mathrm{i}}$ represents the carbon emissions embodied in export of each industry of manufacturing, and $\mathrm{j}$ represents different industries or different countries. $e_{j}$ represents the export volume of each industry of manufacturing or the export volume from China to each country. E represents the total volume of manufacturing export. Meanwhile, $\mathrm{M}^{\mathrm{ex}}$ represents the characteristics of manufacturing trade scale, $S^{\text {ex }}$ represents the characteristics of manufacturing trade structure, the embodied carbon emissions per unit of trade, $T^{\mathrm{ex}}$ represents the embodied carbon emissions efficiency of manufacturing trade. Therefore, the driving factors of manufacturing carbon emissions embodied in export are decomposed into scale effect, structural effect and technical effect. For export embodied carbon, the additive decomposition formulas of LMDI are as follows:

$$
\begin{aligned}
\Delta C_{j}^{e x}=C_{j}^{e x 1}-C_{j}^{e x 0} & =\Delta C_{M^{e x}}+\Delta C_{S^{e x}}+\Delta C_{T^{e x}}+\Delta C_{r s d} \\
\Delta C_{M} & =L\left(C^{1}, C^{0}\right) \ln \left(\frac{M^{1}}{M^{0}}\right) \\
\Delta C_{S} & =L\left(C^{1}, C^{0}\right) \ln \left(\frac{S^{1}}{S^{0}}\right) \\
\Delta C_{T} & =L\left(C^{1}, C^{0}\right) \ln \left(\frac{T^{1}}{T^{0}}\right)
\end{aligned}
$$

$$
\text { Among them, } L\left(C^{1}, C^{0}\right)=\frac{C^{1}-C^{0}}{\ln \left(\frac{C^{1}}{C^{0}}\right)}
$$

In the formulas, $\Delta \mathrm{C}_{\mathrm{M}}, \Delta \mathrm{C}_{\mathrm{S}}$ and $\Delta \mathrm{C}_{\mathrm{T}}$ respectively represent the contribution of scale effect, structural effect and technical effect to export embodied carbon emissions. $\Delta \mathrm{C}_{\mathrm{rsd}}$ is the decomposition margin; the value is 0 ; Phase 1 and phase 0 represent the current and base periods, respectively. After calculation, if the contribution value is positive, it indicates that it contributes to $\Delta \mathrm{C}^{\mathrm{ex}}$, that is, it has played a role in driving the export embodied carbon emissions; conversely, if the contribution value is negative, it indicates that it has no contribution to $\Delta \mathrm{C}^{\mathrm{ex}}$, that is, it has a restraining effect on export embodied carbon emissions. At the same time, in order to study the export embodied carbon emissions more clearly, this paper uses the LMDI method to decompose the drivers of export embodied carbon emissions in the form of multiplication, and calculates the contribution rate of each driver. A contribution rate of more than 1 represents pulling effect, while less than 1 represents inhibiting effect. The calculation formula is as follows:

$$
D=\frac{C^{1}}{C^{0}}=D_{M} D_{S} D_{T} D_{r s d}
$$

Among them, $\mathrm{D}_{\mathrm{M}}, \mathrm{D}_{\mathrm{S}}$ and $\mathrm{D}_{\mathrm{T}}$ are the contribution rate of trade scale factor, trade structural factor and technical factor to export embodied carbon emissions respectively, $\mathrm{D}_{\mathrm{rsd}}$ is the decomposition margin, and phase 1 and phase 0 represent the current period and base period respectively. Take logarithm on both sides of equation (20), and get:

$$
\ln D=\ln D_{M}+\ln D_{S}+\ln D_{T}+\ln D_{r s d}
$$

In contrast to equations (15) and (21), the corresponding proportion of each item can be assumed, namely:

$$
\frac{\ln D}{\Delta C}=\frac{\ln D_{M}}{\Delta C_{M}}=\frac{\ln D_{S}}{\Delta C_{S}}=\frac{\ln D_{T}}{\Delta C_{T}}=\frac{\ln D_{r s d}}{\Delta C_{r s d}}
$$

Here, it is assumed that $0 / 0$ can be an arbitrary constant.

$$
\begin{aligned}
& \text { Set } \frac{\ln D}{\Delta C}=\frac{\ln C^{1}-\ln C^{0}}{C^{1}-C^{0}}=W, \text { then } \\
& D_{M}=\exp \left(W \Delta C_{M}\right), \quad D_{S}=\exp \left(W \Delta C_{S}\right), \\
& D_{T}=\exp \left(W \Delta C_{T}\right), \quad D_{r s d}=1
\end{aligned}
$$

\section{Data Sources}

(1) The MRIO model requires data from three aspects: input-output table of each "the Belt and Road" countries, export volume from China to each country along "the Belt and Road", and $\mathrm{CO}_{2}$ emissions data of each country's sectors. The input-output tables of this paper are from OECD database which contains only 26 countries along "the Belt and Road", including Czech Republic, Estonia, Greece, Hungary, Israel, Latvia, Lithuania, Poland, Slovakia, Slovenia, Turkey, India, Indonesia, Russia, Cambodia, Malaysia, Philippines, United Arab Emirates, Thailand, Bulgaria, Romania, Croatia, Cyprus, Brunei, Singapore and Vietnam. From 2000 to 2015, China's manufacturing exports to the above 26 countries along "the Belt and Road" increased by $16.63 \%$, and its growth trend was almost the same as China's manufacturing exports to all countries along "the Belt and Road". So the latest input-output data of the above 26 countries along "the Belt and Road" and China from 2000 to 2015 are selected. The export data come from the OECD STAN bilateral trade database, which has a sectoral classification similar to that of the OECD input-output table. 
Table 1. Standard volume conversion coefficients and carbon emissions coefficients of various energy sources.

\begin{tabular}{|c|c|c|c|c|c|c|c|c|c|}
\hline Fuel Type & Coal & Coke & Crude oil & Gasoline & Kerosene & Diesel & Fuel oil & $\begin{array}{c}\text { Natural } \\
\text { gas }\end{array}$ & $\begin{array}{c}\text { Electric } \\
\text { power }\end{array}$ \\
\hline $\begin{array}{c}\text { Standard coal conversion } \\
\text { coefficient }\end{array}$ & 0.7143 & 0.9714 & 1.4286 & 1.4714 & 1.4714 & 1.4571 & 1.4286 & 13.3 & 1.229 \\
\hline $\begin{array}{c}\text { Carbon emissions coefficient } \\
(\mathrm{TC} / \mathrm{t})\end{array}$ & 0.7476 & 0.1128 & 0.5854 & 0.5532 & 0.3416 & 0.5913 & 0.6176 & 0.4479 & 2.2132 \\
\hline
\end{tabular}

(2) In this paper, $\mathrm{CO}_{2}$ emissions are distributed to each sector according to the output ratio of each sector and the $\mathrm{CO}_{2}$ emissions coefficient of each sector is obtained. According to the industry classification method of ISIC4.0, the manufacturing industry in China Energy Statistical Yearbook is matched with the manufacturing industry in OECD database, and 15 manufacturing industry segments are summarized for this study. These segments includes S1 food, beverage and tobacco industry, S2 textile, clothing, leather and related products industry, S3 wood and its products industry, S4 paper and printing industry, S5 coke and refined oil industry, S6 chemicals and pharmaceutical products industry, S7 rubber and plastic products industry, S8 other non-metallic mineral industry, S9 basic metal industry, S10 metal products industry, S11 computer, electronic and optical products industry, S12 electrical equipment industry, S13 machinery and equipment industry, S14 transportation equipment manufacturing industry and S15 other manufacturing industries.

(3) The calculation of energy consumption is based on the data of China's Energy Statistics Yearbook from 2000 to 2015, and is uniformly converted into standard coal according to the energy standard coal coefficient, which is in million tons. Carbon emissions (TC) will be calculated using data of various energy fuels and converted into standard coal units. In terms of the measurement of carbon emissions, this paper mainly adopts the internationally common measurement method of carbon emissions, which is based on the measurement method of IPCC. It mainly uses the carbon emissions generated by the consumption of energy fuels, including coal, gasoline, diesel, natural gas, kerosene, fuel oil, crude oil, electricity and coke. According to the carbon emissions coefficient of energy and the calculation formula of carbon emissions: $T C_{t}=\sum E_{i t} * p_{i}$, China's carbon emissions are calculated. Where, $\mathrm{TC}_{\mathrm{t}}$ is the total carbon emissions in year $\mathrm{t}$, and $E_{i t}$ is the carbon emissions coefficient of the ith energy in year t [24]. The standard volume conversion coefficients and carbon emissions coefficients of various types of energy are shown in Table 1 [25].

(4) The data required by the LMDI method include the embodied carbon emissions from China's manufacturing export, the export volume of China's manufacturing and its sub sectors, and the manufacturing export volume from China to 26 countries along "the Belt and Road" listed above. The embodied carbon emissions from China's manufacturing export are calculated from this paper, and the volume of export required is from the OECD database.

\section{Results and Discussion}

\section{Export Embodied Carbon Emissions of China's Manufacturing}

\section{Analysis by Total Amount}

According to formula (13), the carbon embodied in the export of Chinese manufacturing industry to countries along "the Belt and Road" is calculated. As shown in Table 2.

Fig. 1 is the line chart made according to Table 2. The export embodied carbon emissions of China's manufacturing to countries along "the Belt and Road" continuously increased between 2000 and 2015, from 136.16 million tons in 2000 to 495.25 million tons in 2010, with a total increase of 3.637 times. In 2004, the embodied carbon of export trade reached a peak, and the embodied carbon emissions was 684.26 million tons. This may be due to the excessive investment in some industries in 2004, which increased the consumption of coal, electricity, oil and other energy resources. At this time, China took macro-control measures in time, that is, "cadence braking" excessive investment, so the energy consumption returned to the normal level in 2005. The export embodied carbon emissions fell in

Table 2. Export embodied carbon emissions of Chinas manufacturing in 2000-2015 Unit Million tons.

\begin{tabular}{|c|c|c|c|c|c|c|c|c|}
\hline Year & 2000 & 2001 & 2002 & 2003 & 2004 & 2005 & 2006 & 2007 \\
\hline Export embodied carbon & 136.16 & 99.25 & 116.31 & 281.34 & 684.26 & 309.16 & 443.18 & 408.76 \\
\hline Year & 2008 & 2009 & 2010 & 2011 & 2012 & 2013 & 2014 & 2015 \\
\hline Export embodied carbon & 454.22 & 300.4 & 495.25 & 488.86 & 370.66 & 386.64 & 381.83 & 371.7 \\
\hline
\end{tabular}




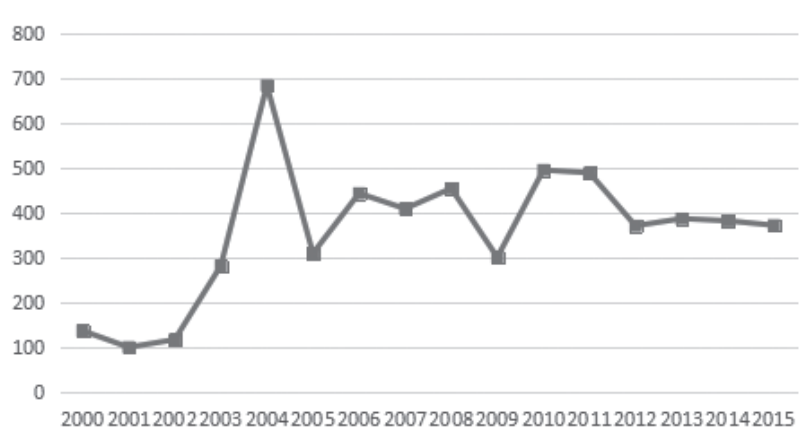

Fig. 1. Export embodied carbon emissions of China's manufacturing industry. Unit: Million tons.

2009 despite of the financial crisis of 2008, but it was still 2.206 times higher than that in 2000. In 2012, the trade war against China's manufacturing enterprises broke out intensively, so there was a significant drop in the carbon emissions embodied in export that year. The carbon emissions embodied in export were borne by China, while goods and services were consumed by countries along "the Belt and Road" [26].

\section{Analysis by Sectors}

Based on the calculation data, the paper mainly analyzes the data of ten industries including S1 food, beverage and tobacco industry, S2 textile, clothing, leather and related products industry, S3 wood and its products industry, S6 chemicals and pharmaceutical products industry, S8 other non-metallic mineral industry, S9 basic metal industry, S11 computer, electronics and optical products industry, S12 electrical equipment industry, S13 machinery and equipment industry, S14 transportation industry, as shown in Fig. 2.

From the perspective of time, from 2000 to 2015, the export embodied carbon of various manufacturing sectors showed an overall upward trend, but the increase rate of each sector varied greatly. Among them, S6, S11, S12, S13 and S14 had the most significant increase in the export of the embodied carbon, which was in the order of: S13, S11, S12, S6 and S14 which increased by 84.415 million tons, 74.177 million tons, 66.398 million tons, 56.405 million tons, and 33.625 million tons, respectively. The export embodied carbon in these sectors increased sharply in 2004, and decreased significantly in 2009 and 2012. The main reason for the great fluctuation in 2004 may be the overheated investment in equipment manufacturing industry, so that the relevant departments increased the export scale to the countries along "the Belt and Road". The export volume of manufacturing industry increased from $\$ 50233.55$ million in 2003 to $\$ 71858.16$ million in 2004, with a growth rate of $30.1 \%$, therefore, the export embodied carbon increased significantly. Due to the impact of the financial crisis in 2008, China's manufacturing market was depressed in 2009, and its export volume dropped from $\$ 234,365.59$ million in 2008 to $\$ 197,043.76$ million, a decline of $15.93 \%$, as a result, the embodied carbon emissions of export trade fell sharply. In 2012, due to the impact of the tightening market environment, the downward pressure on economic operation increased, the manufacturing enterprise management difficulties aggravated and the export situation was not optimistic, so the export embodied carbon of the above five manufacturing industries has significantly reduced. The slowdown in industrial growth in 2009 and 2012 was caused by a number of factors, including the sluggish world economy and persistently low external demand, as well as insufficient effective domestic demand and overcapacity in some industries.

From the perspective of sub-sectors, the sectors with the largest annual export embodied carbon emissions were: S14, S13, S12 and S11. These four sectors were all equipment manufacturing industries,

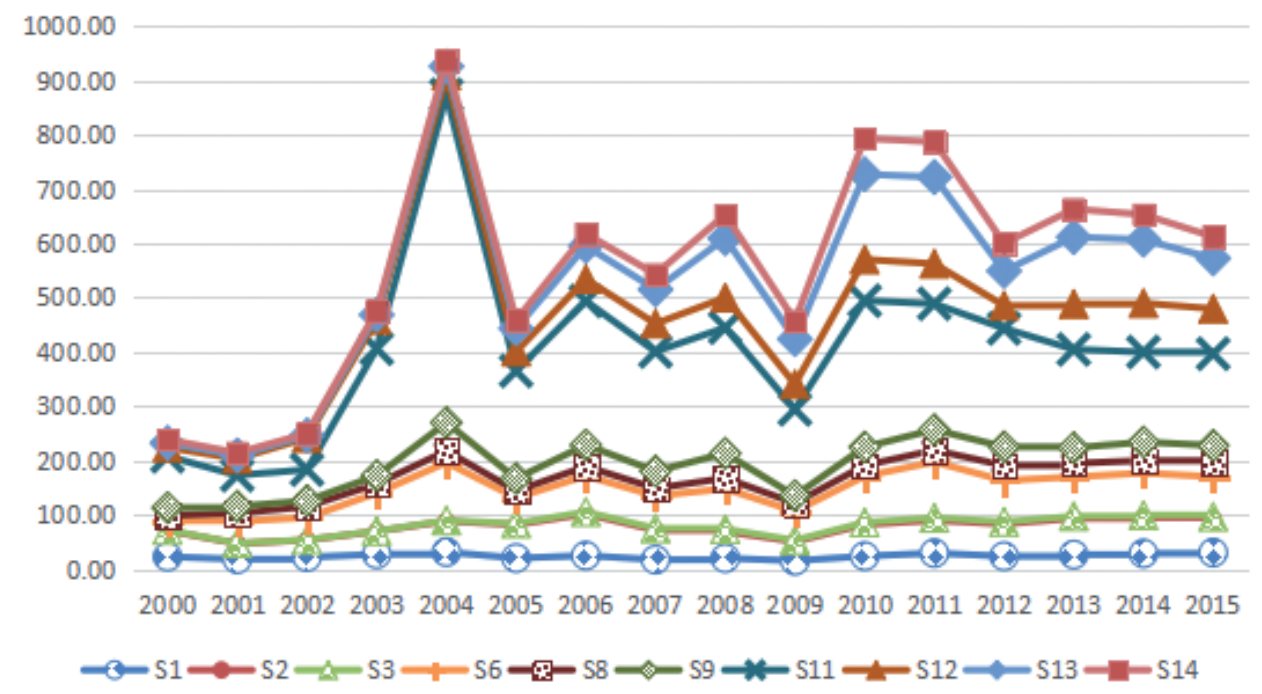

Fig. 2. Export embodied carbon emissions of each sub-sector of China's manufacturing industry. Unit: Million tons. 
led by high and new technology. Beginning in 2003, the gap of export embodied carbon emissions between equipment manufacturing industry, as the engine to promote industrial transformation and upgrading, and other sectors has gradually widened. In 2003, China's manufacturing informatization continued to develop in a positive way, and the dominant position of enterprises significantly strengthened. In 2004, it became a crucial year for the implementation of the "Tenth Five-Year Plan" manufacturing informatization project. With the improvement of the business environment of the manufacturing industry

Table 3. Decomposition results of various factors on the export embodied carbon emissions of typical sectors in typical years.

\begin{tabular}{|c|c|c|c|c|c|c|c|}
\hline \multirow{3}{*}{ Year } & \multicolumn{7}{|c|}{ S9 Basic Metal Industry } \\
\hline & \multicolumn{4}{|c|}{ Contribution value/Million tons } & \multicolumn{3}{|c|}{ Contribution rate } \\
\hline & Scale Effect & Structural Effect & Technical Effect & Gross Effect & Scale Effect & Structural Effect & Technical Effect \\
\hline 2004 & 30.95 & -4.60 & 17.73 & 44.08 & 2.85 & 1.39 & 0.90 \\
\hline 2009 & 29.05 & -3.72 & 10.58 & 35.91 & 7.81 & 0.94 & 0.13 \\
\hline 2012 & 61.81 & -4.59 & -2.32 & 54.90 & 14.50 & 1.41 & 0.11 \\
\hline 2015 & 62.88 & -4.62 & -1.82 & 56.43 & 17.63 & 1.62 & 0.07 \\
\hline \multirow{3}{*}{ Year } & \multicolumn{7}{|c|}{ S11 Computer, Electronic and Optical Products Industry } \\
\hline & \multicolumn{4}{|c|}{ Contribution value/Million tons } & \multicolumn{3}{|c|}{ Contribution rate } \\
\hline & Scale Effect & Structural Effect & Technical Effect & Gross Effect & Scale Effect & Structural Effect & Technical Effect \\
\hline 2004 & 287.06 & 5.15 & -12.52 & 279.69 & 2.85 & 1.25 & 1.79 \\
\hline 2009 & 254.57 & 4.54 & -18.81 & 240.30 & 7.81 & 1.22 & 0.18 \\
\hline 2012 & 394.73 & 8.49 & -14.70 & 388.52 & 14.50 & 0.93 & 0.17 \\
\hline 2015 & 367.16 & 5.22 & -23.91 & 348.47 & 17.63 & 0.92 & 0.11 \\
\hline \multirow{3}{*}{ Year } & \multicolumn{7}{|c|}{ S12 Electrical Equipment Industry } \\
\hline & \multicolumn{4}{|c|}{ Contribution value/Million tons } & \multicolumn{3}{|c|}{ Contribution rate } \\
\hline & Scale Effect & Structural Effect & Technical Effect & Gross Effect & Scale Effect & Structural Effect & Technical Effect \\
\hline 2004 & 25.98 & -0.69 & -12.16 & 13.13 & 2.85 & 1.00 & 0.76 \\
\hline 2009 & 59.16 & 1.20 & 13.92 & 74.28 & 7.81 & 1.20 & 0.30 \\
\hline 2012 & 72.67 & 4.08 & 9.07 & 85.82 & 14.50 & 1.24 & 0.14 \\
\hline 2015 & 117.74 & 15.71 & -15.97 & 117.49 & 17.63 & 1.37 & 0.21 \\
\hline \multirow{3}{*}{ Year } & \multicolumn{7}{|c|}{ S13 Machinery and Equipment Industry } \\
\hline & \multicolumn{4}{|c|}{ Contribution value/Million tons } & \multicolumn{3}{|c|}{ Contribution rate } \\
\hline & Scale Effect & Structural Effect & Technical Effect & Gross Effect & Scale Effect & Structural Effect & Technical Effect \\
\hline 2004 & 12.59 & -0.51 & 2.53 & 14.60 & 2.85 & 1.08 & 0.66 \\
\hline 2009 & 66.56 & 1.48 & -10.56 & 57.49 & 7.81 & 1.68 & 0.77 \\
\hline 2012 & 72.47 & 1.90 & -1.32 & 73.06 & 14.50 & 1.69 & 0.32 \\
\hline 2015 & 100.00 & 2.49 & -14.51 & 87.98 & 17.63 & 1.56 & 0.41 \\
\hline \multirow{3}{*}{ Year } & \multicolumn{7}{|c|}{ S14 Transportation Equipment Manufacturing Industry } \\
\hline & \multicolumn{4}{|c|}{ Contribution value/Million tons } & \multicolumn{3}{|c|}{ Contribution rate } \\
\hline & Scale Effect & Structural Effect & Technical Effect & Gross Effect & Scale Effect & Structural Effect & Technical Effect \\
\hline 2004 & 8.96 & 4.20 & -49.67 & -36.51 & 2.85 & 0.58 & 1.13 \\
\hline 2009 & 33.40 & 18.07 & -78.02 & -26.54 & 7.81 & 1.10 & 0.63 \\
\hline 2012 & 56.64 & 23.53 & -98.40 & -18.24 & 14.50 & 1.12 & 0.51 \\
\hline 2015 & 51.78 & 21.52 & -95.96 & -22.66 & 17.63 & 0.92 & 0.40 \\
\hline
\end{tabular}


and the national policy of vigorously developing the equipment manufacturing industry, the output value of the equipment manufacturing industry has increased greatly since 2003. China's transportation and equipment manufacturing industry, machinery and equipment industry, electrical equipment industry, computer, electronics and optical products industry also greatly increased the export scale to the countries along "the Belt and Road", from \$16209.48 million in 2002 to $\$ 22,489.21$ million in 2003 , an increase of $38.7 \%$. Therefore, the export embodied carbon emissions of these four industries were significantly different from that of other industries.

\section{Decomposition of Export Embodied Carbon Emissions Drivers of China's Manufacturing}

Taking 2000 as the base period and 2001-2015 as the calculation periods through calculation, we can get the contribution values and contribution rates of the scale factor, structural factor and technical factor of the carbon emissions embodied in the manufacturing sub-sectors' export from China to the countries along "the Belt and Road". As can be seen from Table 3, compared with the base period in 2000, S9 basic metal industry, S11 computer, electronics and optical products industry, S12 electrical equipment industry, and S13 machinery and equipment industry all had an increase in export embodied carbon. The export of S11 computer, electronics and optical products industry had the largest increase in embodied carbon, and only the S14 transportation equipment manufacturing industry had a decrease in embodied carbon.

The scale effect had a positive effect on the export embodied carbon in four sectors including S9, S11, S12 and S13, indicating that the expansion of the export scale of these sectors in China during this period promoted carbon dioxide emissions. The technical effect had a negative effect on S11 and S14, which was conducive to reducing the export embodied carbon. The impact of structural effects on the export embodied carbon in various sectors was also different; it had a negative effect on the export embodied carbon emissions of S9. The structural effect had a positive effect on S11 and S14. The reason may be that many countries along "the Belt and Road" include Southeast Asian countries, such as Vietnam and Cambodia, which have accelerated the industrialization process and accelerated the pace of infrastructure construction in recent years. This has created a market for China to shift its heavy and chemical industries, which were suffering from severe overcapacity. Most of China's export trade structure is dominated by labor-intensive products, which has increased the export embodied carbon emissions of China. For S12 and S13, although there have been negative effects in some years, on the whole, it still played a positive role. The main reason for this phenomenon is that China's exports contained many labor-intensive products, and they have undertaken part of the carbon emissions for the countries along "the Belt and Road". The export embodied carbon of S11 increased greatly, which was caused by the combination of scale effect and structural effect. Although the technical effect of this sector could offset part of it, its influence was far lower than the scale effect and structural effect. The technical effect of S14 was negative, that is, it was conducive to reducing the export embodied carbon, and its negative effect could offset the scale effect and structural effect, resulting in a reduction in the export embodied carbon of this sector.

Since 2012, the contribution rate of scale effect to the export embodied carbon of five sectors including S9, S11, S12, S13 and S14 increased significantly. China's foreign trade scale has a very significant effect on embodied carbon emissions. Even with the change of time, the contribution value of technical effect to the export embodied carbon has continued to increase, but the contribution rate of technical effect was still low, indicating that in recent years, China's economy has developed rapidly and its trade scale has been expanding. However, due to the impact of manufacturing production technology, China's current energy consumption is still relatively large, production efficiency is low, and the intensity of carbon dioxide emissions of pollutants could not be well controlled.

\section{Conclusion}

In this paper, the MRIO model is used to calculate the export embodied carbon emissions of China's manufacturing from 2000 to 2015, and the LMDI method for the study is established to explore the export embodied carbon emissions drivers of manufacturing from the aspects of scale effect, structural effect and technical effect. The main research conclusions are as follows:

(1) During the period from 2000 to 2015, the export embodied carbon emissions of manufacturing from China to the countries along "the Belt and Road" have been increasing slowly. It shows that in recent years, the export embodied carbon emissions of manufacturing have been borne by China, while goods and services have been consumed by countries along "the Belt and Road".

(2) From the perspective of sub-sectors, the sectors that have the highest export embodied carbon emissions each year are equipment manufacturing industries. Beginning in 2003, the gap of export embodied carbon emissions between equipment manufacturing industry, as the engine to promote industrial transformation and upgrading, and other sectors gradually widened. China's continuous policies in favor of the development of the equipment manufacturing industry have greatly increased the output value of the equipment manufacturing industry since 2003, and China's export scale to the countries along "the Belt and Road" has also 
increased significantly, so that it promotes the growth of export embodied carbon emissions.

(3) In terms of the driving factors of the export embodied carbon emissions of China's manufacturing, the scale of manufacturing export trade has the largest impact on the embodied carbon emissions of China's export trade, and has played a strong driving role. The optimization of the export trade structure of manufacturing industry has played a role in restraining the export embodied carbon emissions of China's basic metal industry, and the inhibitory effect slowly enhanced. However, the optimization of the export trade structure of manufacturing industry has a positive effect on the computer, electronic and optical products industry, electrical equipment industry, machinery and equipment industry, and transportation equipment manufacturing industry. For instance, the pulling effect on the electrical equipment industry and the transportation equipment industry has increased significantly in recent years. The export embodied carbon emissions intensity of the manufacturing industry has shown a restraining effect on most manufacturing industries, and the improvement of the restraining effect is more obvious. Generally speaking, this shows that with the continuous expansion of the scale of manufacturing export, the optimization of export structure and the reduction of carbon emissions intensity can curb the increase of export embodied carbon emissions of China's manufacturing.

Therefore, in the future, China should take optimizing the manufacturing export trade structure and reducing the intensity of carbon emissions as important paths to reduce the embodied carbon emissions of manufacturing industries to the countries along "the Belt and Road", so as to achieve green development in the whole manufacturing chain of China's manufacturing industry, including the acquisition of raw materials, manufacturing, processing and transportation. (1) Extend the manufacturing industry value chain and realize the shift of the industrial value chain to the high end. Optimize the export structure through technological improvement and industrial structure upgrading, reduce the export share of labor-intensive products, and increase the export share of capital intensive products [27]. In the manufacturing and processing process of manufacturing industry, China should improve the precision of processed products, divide the upstream and downstream environment of products carefully, attract the production links with high technology and high added value of multinational companies to provide technical equipment and advanced technology for the low-carbon development of the whole production chain of China's manufacturing industry, and realize the gradual transformation of manufacturing industry from labor-intensive to capital-intensive and technologyintensive [28]. (2) Vigorously develop low-carbon and environmentally-friendly industries. When introducing foreign direct investment projects in manufacturing industry, it is necessary to incline to green low-carbon projects, make full use of renewable resources, fully develop new clean energy products, innovate lowcarbon technologies and improve production efficiency in manufacturing industry [29]. In addition, China should accelerate the development of producer service industries that are compatible with the manufacturing and transportation processes in the manufacturing industry, realize specialized division and cooperation, formulate the development strategy and improve the relevant mechanisms of producer services industries, strive to guide the production and transportation of China's manufacturing industry with the concept of "low-carbon", and reduce the export embodied carbon emissions of China's manufacturing industries to the countries along "the Belt and Road".

(3) Strengthen the supervision of manufacturing enterprises and provide policy support to low-carbon and environmentally-friendly enterprises. Improve the access system of manufacturing export enterprises and strictly restrict the export of "high energy consumption, high pollution and resource manufacturing products". The social liability of reducing carbon emissions must be included in the assessment scope of manufacturing enterprises. In case of any illegal production of manufacturing enterprises, it shall be stopped in time and punished severely; manufacturing enterprises with severe pollution must be guided by "Low Carbon". At the same time, reasonable identification should be given to manufacturing enterprises engaged in hightech production so that the enterprises can enjoy related preferential policies such as tax reductions and financial supports.

Our research also has some limitations. The OECD database was only updated to 2015 , and the availability of the research data of the thesis is still insufficient. In the follow-up research, we will focus on the embodied carbon transfer of various industries between China and the countries along "the Belt and Road" from the perspective of "the Green Belt and Road", and explore whether the trade behavior conforms to the concept of "the Green Belt and Road" for making "the Belt and Road" construction more green and less carbonized.

\section{Acknowledgements}

This work was supported by Research on the Cooperation and Sharing Mechanism of Global Value Chain of Equipment Manufacturing Industry Along "the Belt and Road" (the National Social Science Fund Project, Serial Number: 17BJY071).

\section{Conflict of Interest}

The authors declare no conflict of interest. 


\section{References}

1. CHEN X.R. Research on the impact of "the Belt and Road" construction on the internationalization of the RMB [D]. Hebei University, 2019.

2. WEI B.Y., FANG X.Q., WANG Y., YANG H.M., ZHANG D. Estimation of carbon emissions embodied in international trade for China:an input-output analysis [J]. Journal of Beijing Normal University(Natural Science), 45 (04), 413, 2009.

3. ZHU Y.B., SHI Y.J., WU J.,WU L.Y.,XIONG W. Exploring the characteristics of $\mathrm{CO}_{2}$ emissions embodied in international trade and the fair share of liability $[\mathrm{J}]$. Ecological Economics, 146, 574, 2018.

4. LI F.J. Progress and prospects of research on transfer of carbon emissions embodied in inter-regional trade [J]. Progress in Geography, 37(10), 1303, 2018.

5. HUANG M., WU S.L. The origin and progress of embodied carbon in foreign trade [J]. Journal of Shanghai Business School, 11 (02), 77, 2010.

6. MA S.Z., CHEN Y. The influence of international trade to China's embodied carbon emissions during 2000-2009:based on consumption and SRIO model [J]. Finance and Trade Economics, (12), 82, 2010 .

7. LIU Q.Y. Research on calculation and influencing factors of embodied carbon emissions in Inter-Provincial trade of Shanxi province:based on MRIO-SDA method [D]. Shanxi University, 2018.

8. YAN Y.F., ZHAO Z.X., WANG R. China's emissions responsibility and trade-embodied emissions: a MRIO approach [J]. World Economy Study, (06), 54, 2013.

9. PANG J., SHI Y.C., XIE X., GAO X.M. Study on the carbon embodied in trades of China,the United States,EU and Japan using the MRIO model [J]. Climate Change Research, 11 (03), 212, 2015.

10. LI C., CONG R., SHAO G.L.Embodied carbon emissions transfer in China aquatic product trade based on MRIO modeling and LMDI methods [J]. Resources Science, 40 (05), 1072, 2018.

11. YAN Y.F., ZHAO Z.X., WANG R. The $\mathrm{CO}_{2}$ emissions embodied in China - EU trade: an Input-output approach [J]. Finance and Trade Research, 23 (02), 76, 2012.

12. PAN A., WEI L. Embodied carbon in China's foreign trade:structural features and influential factors [J]. Economic Review, (04), 16, 2016.

13. DENG R.R., CHEN M. Concealed carbon emissions in Sino-US Trade - analysis based on I-O SDA model [J]. Management Review, 26 (09), 46, 2014.

14. LI Y.M., FU J.F.Structural decomposition analysis on carbon emissions growth embodied in exports in China [J]. China Population, Resources and Environment, 20(08), 53, 2010.

15. ZHANG Z.J. Accounting and structural decomposition analysis of multi-regional embodied carbon trade in China [J]. Statistics and Decision, (13), 125, 2017.
16. WANG H.J., XIA Y. Influence factors VS. developments of China's household carbon emissions [J]. Chinese Journal of Management Science, 25 (08), 1, 2017.

17. ZHAO Y.H., WANG S. Environmental technology, environmental regulation and whole process management - evidence from comparison between $10^{\text {th }}$ and $11^{\text {th }}$ FYP [J]. Journal of Beijing Institute of Technology(Social Sciences Edition), 16 (01), 12, 2014.

18. QIAN Z.Q., YANG L.K. The impact of east Asia vertical specialization on China's embodied carbon emissions: an inter-temporal MRIO-SDA analysis [J]. Resources Science, 38 (09), 1801, 2016.

19. ANG B.W. The LMDI approach to decomposition analysis: A practical guide [J]. Energy Policy, 33, 867, 2005.

20. XU G.Q., LIU Z.Y., JIANG Z.H. Decomposition model and empirical study of carbon emissions for China, 19952004 [J]. China Population, Resources and Environment, (06), 158, 2006.

21. COPELAND B.R., TAYLOR M.S. Is free trade good for the environment? [R]. NBER Working Paper, 2001.

22. HOU F.M., CAI T., YANG Y.X. An empirical study on the influence mechanism of embedded global value chain on trade implied carbon emissions in China [J]. Journal of Nanjing University of Finance and Economics, (06), 28, 2018.

23. PENG X. The study on spatial carbon emissions effect of China's embedding in the manufacturing sector under global value chain perspective [D]. Hunan University, 2012.

24. LEI Y.T., YANG J. A study of regional difference of carbon emissions efficiency based on stochastic frontier analysis [J]. Economic Theory and Business Management, (07), 13, 2014.

25. Sustainable Development Strategy Research Group of Chinese Academy of Sciences. China Sustainable Development Strategy Report in 2009 - Exploring low-carbon path with Chinese characteristics [M]. Beijing:Science Press, 2009.

26. LI Q.R. The embodied carbon in trade of China and Japan with countries along the Belt and Road and their determinants $[\mathrm{J}]$. Contemporary Economy of Japan, 36 (04), 69, 2017.

27. WANG B.Q., CHEN P., DU G., JIANG X.H. A study on the structural decomposition of implied carbon emissions in China's export trade - a comparative analysis based on trade and carbon emissions from China and trade partners [J]. Price: Theory and Practice, (01), 134, 2018.

28. XU J. Research on transformation and upgrading of processing trade in Shandong Province under the background of low carbon economy [D]. Shandong Normal University, 2014.

29. GUO J., YE W.M. Measures and influencing factors of embodied carbon of manufacturing industries export trade in China [J]. Science and Technology Management Research, 35 (07), 214, 2015. 
